\title{
Characteristics of equatorial ionization anomaly (EIA) in relation to transionospheric satellite links around the northern crest in the Indian longitude sector
}

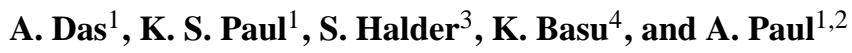 \\ ${ }^{1}$ S. K. Mitra Center for Research in Space Environment, University of Calcutta, 92 Acharya Prafulla Chandra Road, \\ Calcutta-700009, India \\ ${ }^{2}$ Institute of Radio Physics and Electronics, University of Calcutta, 92 Acharya Prafulla Chandra Road, \\ Calcutta-700009, India \\ ${ }^{3}$ Department of Physics, University of North Bengal, Siliguri-734013, India \\ ${ }^{4}$ Department of Physics, K.N. College, Baharampore, Murshidabad, West Bengal-742101, India
}

Correspondence to: A. Das (aditidas16@rediffmail.com)

Received: 16 August 2013 - Revised: 10 December 2013 - Accepted: 24 December 2013 - Published: 12 February 2014

\begin{abstract}
The poleward gradient of the equatorial ionization anomaly (EIA) introduces more intense propagation effects on transionospheric satellite links in comparison to the equatorward gradient. Characterization of the poleward gradient was performed during March-April, August-October 2011 and March-April 2012 using GPS total electron content (TEC) recorded from a chain of stations located more or less along the same meridian $\left(88.5^{\circ} \mathrm{E}\right)$ at Calcutta, Baharampore, Farakka and Siliguri. The poleward gradients calculated on magnetically quiet days at elevation in excess of $50^{\circ}$ at $14: 00$, 15:00 and 16:00 LT were found to have a strong correlation with GPS $S_{4}$ observed from Calcutta during post-sunset-tomidnight hours. A threshold value of poleward TEC gradient is calculated above which there is a probability of scintillation at Calcutta with $S_{4} \geq 0.4$.
\end{abstract}

Keywords. Ionosphere (equatorial ionosphere; ionospheric irregularities) - radio science (ionospheric propagation)

\section{Introduction}

The impact of a developed equatorial ionization anomaly (EIA) in the afternoon hours on the subsequent development of equatorial ionization density irregularities during postsunset hours was suggested by Raghavarao et al. (1988) and validated by several workers (Valladares et al., 2001, 2004; Ray et al., 2006; Rama Rao et al., 2006; Ram et al., 2006;
Nava et al., 2007). However the majority of the validation exercise was performed at locations existing between the magnetic equator and the northern and southern crests of the EIA.

A developed EIA results in a sharp latitudinal gradient not only equatorward of the northern/southern crest but on the poleward side (i.e., total electron content (TEC) gradient from crest to poleward side latitude) as well, the latter being more intense than the former. Beyond the anomaly crest there is sharp decrease of TEC within few degrees of latitudes. While a lot of emphasis has been given to the adverse effects of the sharp gradient of the EIA from the magnetic equator towards the northern crest on SBAS (Satellite Based Augmentation System) operations, very little work has been done on the sharper gradient of ionization existing beyond the northern crest towards the midlatitudes. The issue that concerns to the SBAS system designers is the steeper gradient of the EIA poleward of the northern crest rather than the equatorward side as estimation of an optimum grid size and group delays will be different on either side of the crest. The steeper gradient of the EIA beyond the northern crest has been well illustrated by Rastogi and Klobuchar (1990). Paul et al. (2011) also noticed the difference in latitudinal gradient existing on either side of the northern crest of the EIA.

An unique experiment, in the geographically sensitive Indian perspective, was conducted by the Satellite Beacon and Space Weather Studies group of the Institute of Radio Physics and Electronics, University of Calcutta, Calcutta, 
India, during the equinoxes of 2011 and 2012. A chain of dual-frequency GPS receivers were operated at Calcutta $\left(22.58^{\circ} \mathrm{N}, 88.38^{\circ} \mathrm{E}\right.$ geo, $33.82^{\circ} \mathrm{N}$ mag. dip), Baharampore $\left(24.09^{\circ} \mathrm{N}, 88.25^{\circ} \mathrm{E}\right.$ geo, $34.73^{\circ} \mathrm{N}$ mag. dip), Farakka $\left(24.79^{\circ} \mathrm{N}, 87.89^{\circ} \mathrm{E}\right.$ geo, $36.04^{\circ} \mathrm{mag}$. dip) and Siliguri $\left(26.72^{\circ} \mathrm{N}, 88.39^{\circ} \mathrm{E}\right.$ geo, $39.49^{\circ} \mathrm{N}$ mag. dip), located more or less along $88.5^{\circ} \mathrm{E}$ meridian situated between the northern crest of the EIA and extending well beyond the northern crest up to $40^{\circ} \mathrm{N}$ magnetic dip. Total electron content (TEC) was measured at three stations (Calcutta, Baharampore and Siliguri during the equinoctial period of 2011 and Calcutta, Farakka and Siliguri at vernal equinox of 2012) and the latitudinal gradient of TEC estimated for the poleward side of EIA. The effect of spatial contamination of TEC from GPS satellites was eliminated by using satellite links at elevation angles in excess of $50^{\circ}$. In order to find a correlation between the poleward gradient of TEC calculated during the afternoon hours with post-sunset occurrence of GPS scintillations at Calcutta, situated at the northern crest of EIA, $\mathrm{S}_{4}$ values measured on GPS links within a subionospheric swath of $\pm 1^{\circ}$ in latitude and longitude around Calcutta were used. TEC measurement at locations beyond the northern crest of the EIA in the Indian longitude sector are sparse with the exception of records from Delhi and stations at Simla and Hanley operated under Indian SBAS GAGAN (GPS-Aided Geo-Augmented Navigation). However, to the best of our knowledge, studies correlating the poleward gradient of TEC with post-sunset scintillation occurrence have not been reported from the Indian region. It is important to note that the poleward region of EIA having steeper TEC gradients in comparison to the equatorward side introduces greater range error rates and will pose more challenging situations for reliable SBAS operations.

A specific deliverable from this novel experiment was to develop quantitative relation between the poleward latitudinal gradient of TEC measured during the afternoon hours and the occurrence of post-sunset L-band scintillations from a station near the northern crest of the EIA with a realistic lead time so as to issue effective alarms for SBAS users around this region.

\section{Data}

During the multi-station campaigns, slant total electron content (STEC) and $\mathrm{S}_{4}$ variations are measured for the period of March-April 2011, August-October 2011 and March-April 2012, for moderate sunspot $(\sim 60-120)$ activity year, from three dual-frequency GPS receivers, situated on the northern crest of equatorial ionization anomaly (EIA) and beyond almost along the same geographic longitude $\left(\sim 88.5^{\circ} \mathrm{E}\right)$. The station at Calcutta, operated by the Institute of Radio Physics and Electronics (IRPE), University of Calcutta, Calcutta $\left(22.58^{\circ} \mathrm{N}, 88.38^{\circ} \mathrm{E}\right.$ geo, $33.82^{\circ} \mathrm{N}$ mag. dip), has been part of the international SCINDA (SCIntillation

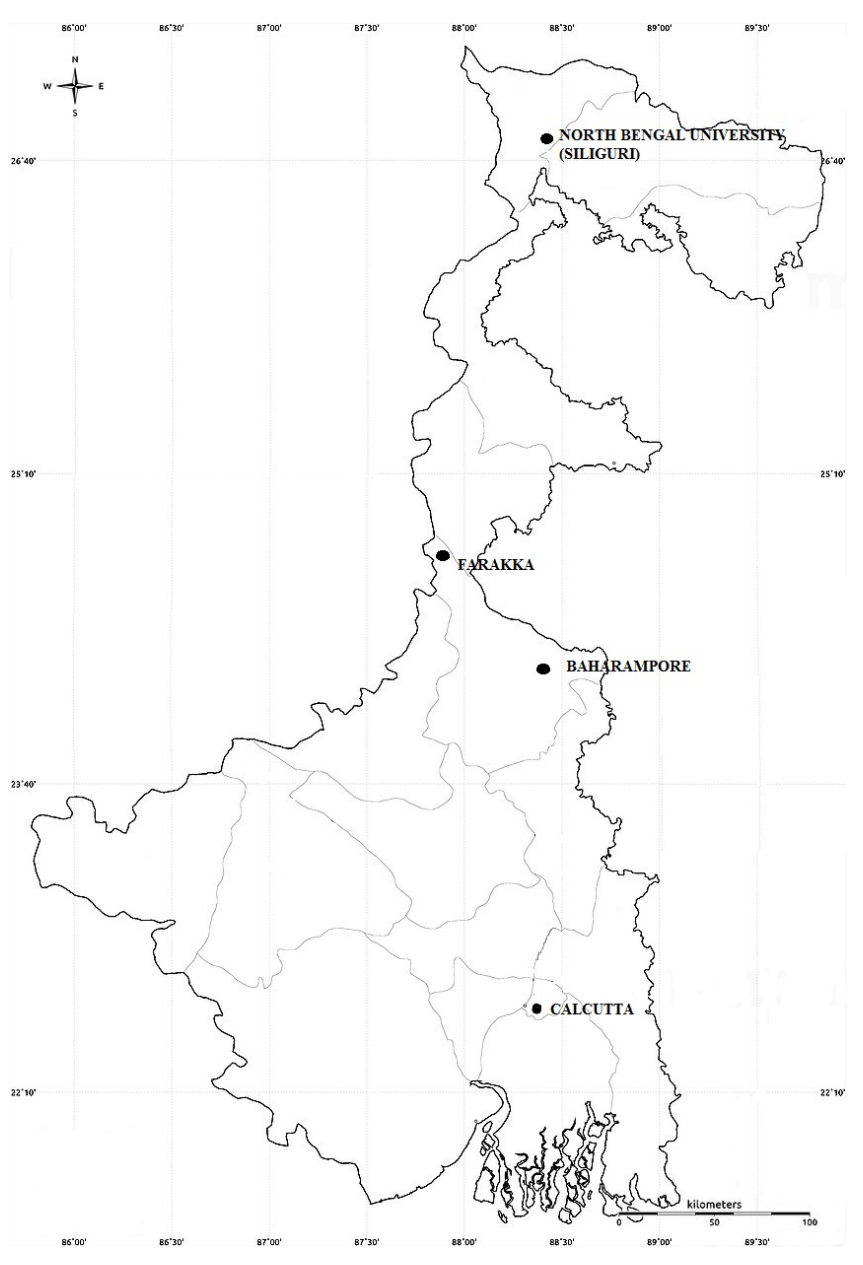

Fig. 1. Locations of dual-frequency GPS receivers in West Bengal, India, used for the measurements.

Network Decision Aid) program of the US Air Force since November 2006, whereby a dual-frequency ionospheric scintillation and TEC monitor is operational continuously providing diurnal TEC plots, scintillation indices $S_{4}$ at $1 \mathrm{~min}$ interval and polar plots corresponding to different satellites observed during the whole day. These data may be accessed in a post-processed format by authorized users.

A software-based dual-frequency high-resolution GPS receiver was operated at the North Bengal University, Siliguri $\left(26.72^{\circ} \mathrm{N}, 88.39^{\circ} \mathrm{E}\right.$ geo, $39.49^{\circ} \mathrm{N}$ mag. dip), during the three equinoctial periods mentioned above. Amplitude and phase scintillation data from this receiver were digitally logged at sampling frequency of $50 \mathrm{~Hz}$ while the TEC data were recorded at 1 min sampling interval.

Another dual-frequency ionospheric scintillation and TEC monitor was operated at K. N. College, Baharampore $\left(24.09^{\circ} \mathrm{N}, 88.25^{\circ} \mathrm{E}\right.$ geo, $34.73^{\circ} \mathrm{N}$ mag. dip), during two equinoxes of 2011 and at Farakka $\left(24.79^{\circ} \mathrm{N}, 87.89^{\circ} \mathrm{E}\right.$ geo, $36.04^{\circ} \mathrm{N}$ mag. dip) during the vernal equinox of 2012 . Here also data are recorded at $1 \mathrm{~min}$ sampling interval. 
To find the poleward TEC gradient of EIA during afternoon hours, when the TEC values maximize, STEC values measured from each station during 07:45-08:15 UT $(\sim 13: 45-14: 15 \mathrm{LT}), \quad 08: 45-09: 15$ UT $(\sim 14: 45-15: 15 \mathrm{LT})$ and 09:45-10:15 UT $(\sim 15: 45-16: 15 \mathrm{LT})$ for an elevation greater than $50^{\circ}$ were used. The measured STEC was converted to equivalent vertical TEC (VTEC) using a slanting factor, which involves the zenith angle at the station. The mapping function used to convert the slant TEC to vertical TEC is given by the

slanting factor $=1 /\left(\left(1-r_{\mathrm{E}} \operatorname{Cos} \mathrm{El} /\left(r_{\mathrm{E}}+h_{\mathrm{M}}\right)^{2}\right)^{1 / 2}\right)$,

where $r_{\mathrm{E}}$ is the radius of the Earth, El is the elevation angle at the receiver location and $h_{\mathrm{M}}$ is the height of the maximum electron density $=350 \mathrm{~km}$ (Breed et al., 1997; Nava et al., 2007).

vertical TEC $=$ slant TEC/slanting factor.

In order to eliminate any longitudinal effect on $S_{4}$, the maximum $S_{4}$ measured at 1 min sampling interval from all satellite links observed from Calcutta above an elevation of $70^{\circ}$ over the time interval 18:00-06:00 LT (local time) was used. The elevation masking was taken greater than $70^{\circ}$ to eliminate the multipath and range rate error effects of a GPS satellite. As geomagnetic activity influences the ionization and hence the TEC, data from different stations have been used only on days when the hourly Dst index was greater than $-50 \mathrm{nT}$ and 3 hourly $\mathrm{Kp}$ index was less than $3+$ during the period of 2011-2012 equinoxes. Therefore in March-April 2011, 26 days are considered out of 34 days; in August-October 2011, 55 days are considered out of 89 days; and in March-April 2012, 39 days are considered out of 45 days in this study.

\section{Results}

Figure $2 \mathrm{a}-\mathrm{c}$ show the representative cases of latitudinal variation of VTEC at 10:00 UT (16:00 LT) along 88.5 meridian, measured from three stations on 24 April 2011, 3 September 2011 and 12 April 2012 respectively for an elevation greater than $50^{\circ}$. The differences in latitudinal gradient between the two sides of the northern crest of EIA are clearly noted from the figures. It is also noticed that the poleward TEC gradient is sharper than the equatorward TEC gradient. From Fig. 2a it is calculated that on 24 April 2011 the equatorward TEC gradient was $6.9 \mathrm{TECU} \mathrm{deg}^{-1}$, while the poleward TEC gradient was 11.6 TECU deg ${ }^{-1}$. Similarly from Fig. $2 b$ and c, it is found that on 3 September 2011 and 12 April 2012 the equatorward TEC gradients were

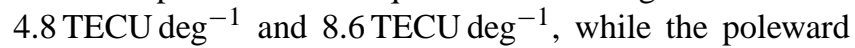
TEC gradients were 13.6 TECU deg ${ }^{-1}$ and 9.8 TECU deg $^{-1}$, respectively. (a)

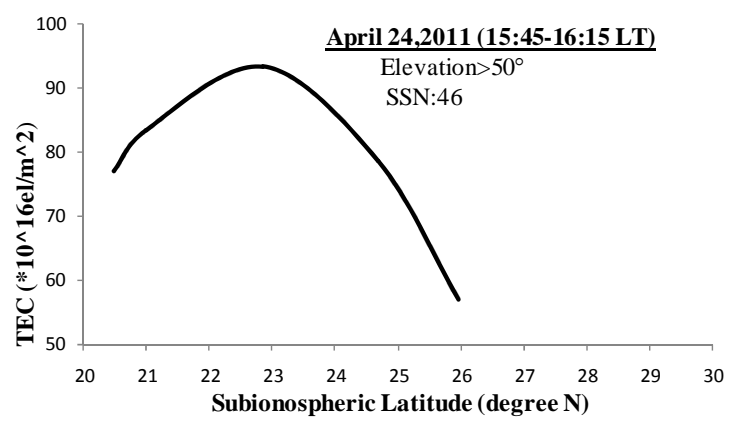

(b)

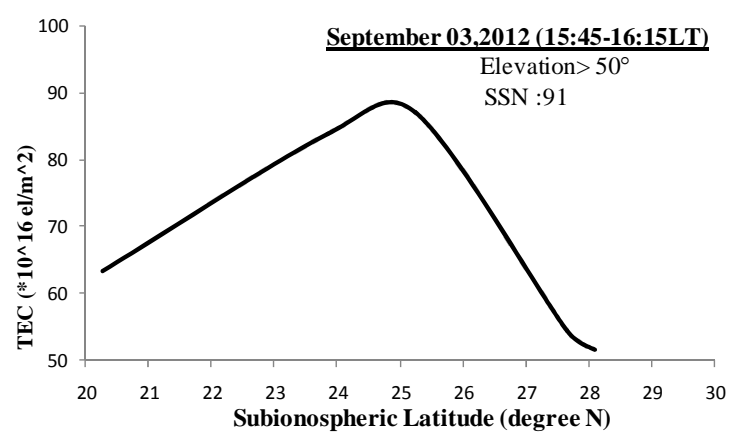

(c)

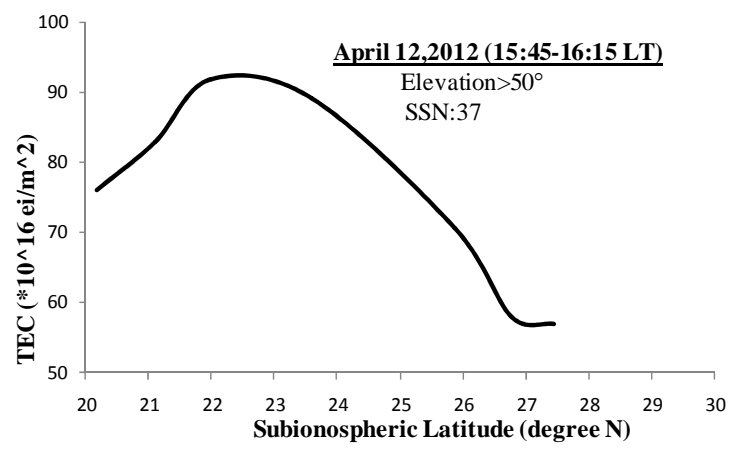

Fig. 2. (a-c) Latitudinal gradient of VTEC, existing away from the magnetic equator to the northern crest of EIA and beyond, measured at three stations with elevation angles greater than $50^{\circ}$ at different subionospheric latitudes ranging from $20^{\circ} \mathrm{N}$ to $30^{\circ} \mathrm{N}$ on 3 days, namely, 24 April 2011, 3 September 2011 and 12 April 2012.

The spatial variation of TEC on 24 April 2011 over a subionospheric latitude range of $20^{\circ}-26^{\circ} \mathrm{N}$ and longitude $85^{\circ}-90^{\circ} \mathrm{E}$ at $16: 00 \mathrm{LT}$ is shown in Fig. 3a combining TEC data from the two stations, Calcutta and Baharampore, at elevation angles greater than $50^{\circ}$. It is found from the figure that the northern crest of EIA lies between $22.5^{\circ}$ and $23^{\circ} \mathrm{N}$, and the separations between the constant TEC lines are greater south of EIA compared to the separation to the north; i.e. the poleward TEC gradient is greater than the equatorward TEC gradient. Similarly the contours of TEC for 3 September 2011 and 12 April 2012 bounded by the region $20^{\circ}-$ $28^{\circ} \mathrm{N}$ subionospheric latitude and $85^{\circ}-90^{\circ} \mathrm{E}$ subionospheric longitude are shown in the Fig. $3 \mathrm{~b}$ and c, respectively, where observations were taken from the three stations Calcutta, Baharampore and Siliguri. The peak of TEC is found around 
(a) APRIL 24,2011(1545-1615 LT)

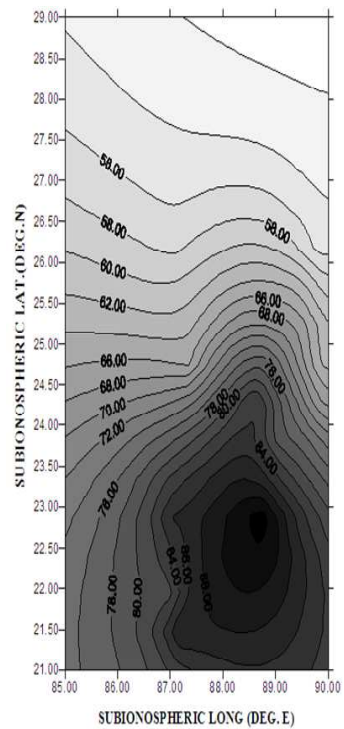

(b) SEPTEMBER03, 2011(1545-1615 LT)

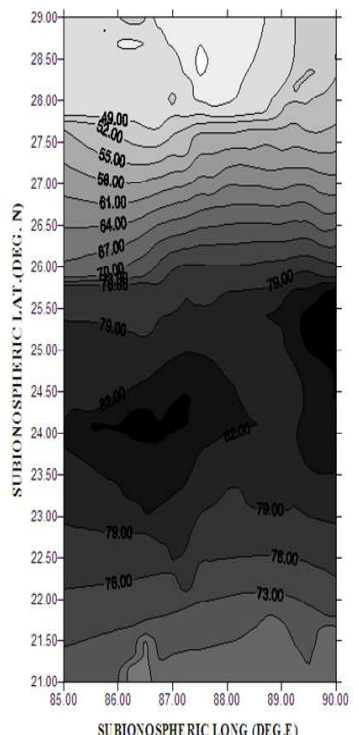

(c) APRIL 12,2012 (1545-1615 LT)

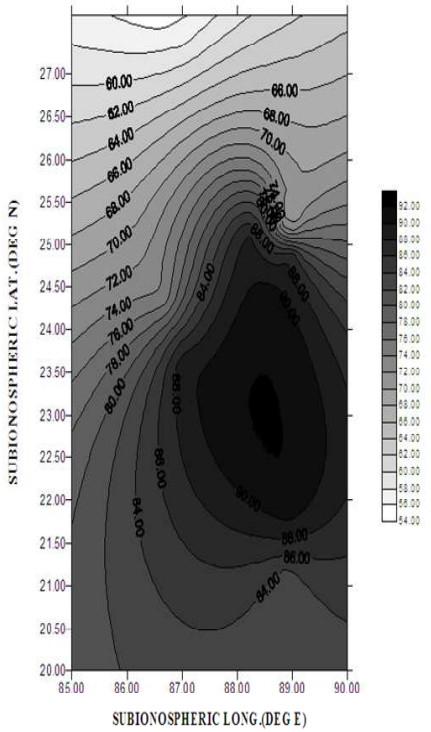

Fig. 3. (a-c) Contours of measured VTEC at 10:00 UT ( 16:00 LT) on 3 days 24 April 2011, 3 September 2011 and 24 April 2012 at different subionospheric longitudes and latitudes ranging from $85^{\circ} \mathrm{E}$ to $90^{\circ} \mathrm{E}$ and $20^{\circ} \mathrm{N}$ to $29^{\circ} \mathrm{N}$ (except 12 April 2012 ), respectively, and for 12 April 2012 subionospheric latitude ranges from $20^{\circ} \mathrm{N}$ to $27^{\circ} \mathrm{N}$.

$24^{\circ} \mathrm{N}$ on 3 September 2011 and $23^{\circ} \mathrm{N}$ on 12 April 2012. In both cases, the gradient of TEC beyond the anomaly crest was found to be greater than the gradient from the equator to anomaly crest. Poleward TEC gradients were calculated for the whole observational periods during the equinoxes of 2011 and 2012 from these contours taking the TEC values from $24^{\circ} \mathrm{N}$ to $26^{\circ} \mathrm{N}$ at $88.5^{\circ} \mathrm{E}$ meridian.

There are several studies relating the equatorward TEC gradient with the occurrence of post-sunset scintillations (Raghavarao et al., 1988; Ray et al., 2006). This is perhaps for the first time that efforts are being made to correlate occurrence of post-sunset scintillations with the poleward TEC gradient in the Indian longitude sector. To correlate the calculated poleward gradient of TEC with the occurrence of scintillations during the equinoctial periods of 2011-2012, observed from the GPS satellite data, maximum $S_{4}$ observed on a particular night at elevation $>70^{\circ}$ from Calcutta over a subionospheric swath of $87.5^{\circ}-89.5^{\circ} \mathrm{E}$, $21.5^{\circ}-23.5^{\circ} \mathrm{N}$ during 18:00-06:00 LT was used. A threshold value of $S_{4}=0.4$ was considered for this analysis. The variation of $S_{4}$ with poleward gradient of TEC during MarchApril 2011 at 14:00, 15:00 and 16:00 LT is shown in Fig. 4ac, respectively. The $x$ axis represents the poleward TEC gradient during afternoon hours and $y$ axis the maximum $S_{4}$ value on that day during the post-sunset hours. The nights with $S_{4} \geq 0.4$ are represented by "circles", and the nights with $S_{4}<0.4$ are indicated by "crosses". The horizontal line in the plot is the constant $S_{4}=0.4$ line. Similarly Figs. 5a-c and $6 \mathrm{a}-\mathrm{c}$ represent the correlation during the autumnal equinox of 2011 and vernal equinox of
2012. To find a correlation between the poleward TEC gradient measured during afternoon hours with the maximum value of $S_{4}$ in the post-sunset hours, a threshold value of

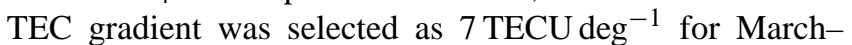
April 2011, $8 \mathrm{TECU} \mathrm{deg}^{-1}$ for August-October 2011 and 11 TECU deg ${ }^{-1}$ for March-April 2012, above which most of the cases of scintillations with $S_{4} \geq 0.4$ were observed from Calcutta. The vertical line in the Figs. $4 a-c, 5 a-c$ and $6 a-c$ represents these threshold values. Chi-square $\left(\chi^{2}\right)$ test was performed with these threshold values at 14:00, 15:00 and 16:00 LT respectively for each equinox. The chi-square distribution table during 14:00, 15:00 and 16:00 LT for the period March-April 2011 is listed in Table 2. Similarly, Tables 3 and 4 represent the same for the autumnal equinox of 2011 and vernal equinox of 2012 respectively. Finally the chi-square values for each equinox are given in Table 5. A highly significant association at $1 \%$ level was noted on 14:00 LT during the vernal equinox of 2011 and $0.1 \%$ level at 15:00 and 16:00 LT during the vernal equinox of 2011 and at 14:00, 15:00 and 16:00 LT on autumnal equinox of 2011 and vernal equinox of 2012.

Equatorward TEC gradients are also calculated during March-April 2011, August-October 2011 and MarchApril 2012 at 14:00, 15:00 and 16:00 LT. The estimation has been done over a subionospheric latitude range $16^{\circ}-20^{\circ} \mathrm{N}$ so as to include satellite links above an elevation mask of $15^{\circ}$. The threshold value of the equatorward TEC gradient for scintillation with $S_{4} \geq 0.4$ during March-

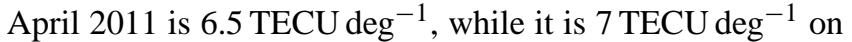
the poleward side. Similarly during August-October 2011 


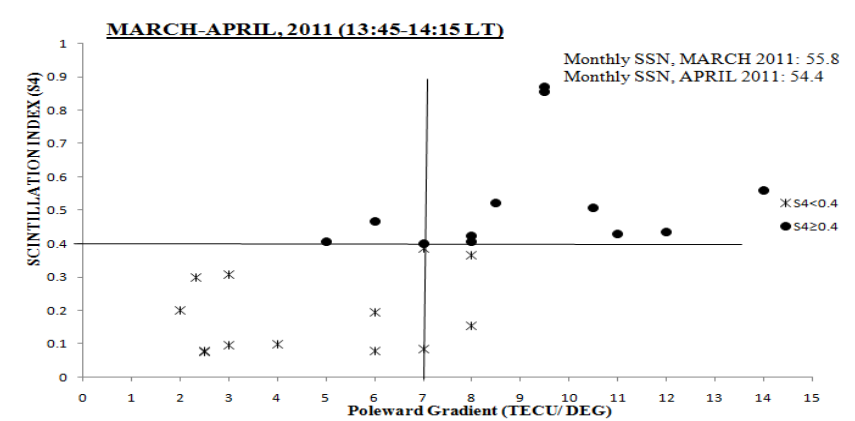

(a)

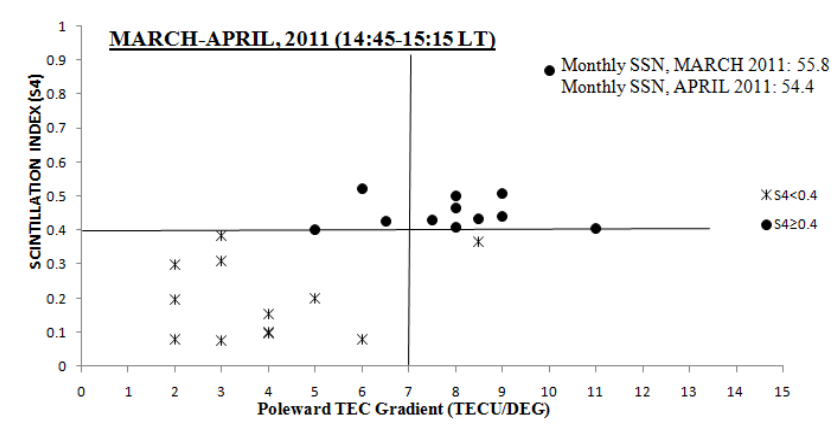

(b)

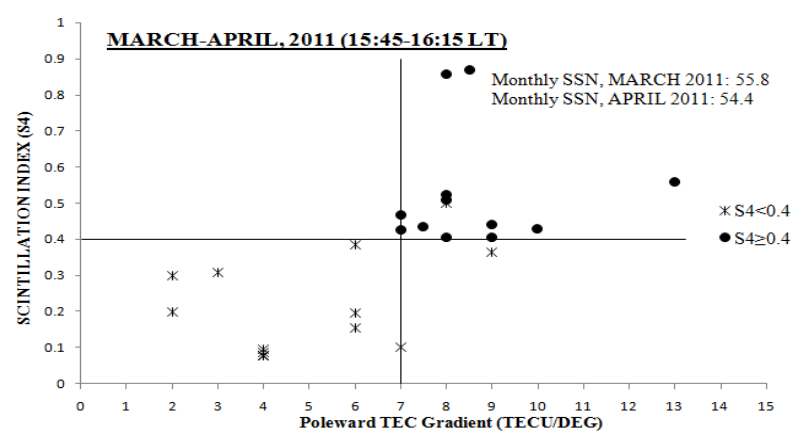

(c)

Fig. 4. (a-c) Correlation of poleward gradient of EIA calculated at 14:00, 15:00 and 16:00 LT, respectively, over subionospheric latitude $24^{\circ}-27^{\circ} \mathrm{N}$ and longitude swath $88.5^{\circ} \mathrm{E}$ on different days of 23 March-30 April 2011 with GPS scintillation $\left(S_{4} \geq 0.4\right)$ around the northern crest of the EIA ( $350 \mathrm{~km}$ subionospheric swath $21.5^{\circ}$ $\left.23.5^{\circ} \mathrm{N}, 87.5^{\circ}-89.5^{\circ} \mathrm{E}\right)$.

Table 1. Position coordinates of four dual-frequency GPS receivers used in the campaigns.

\begin{tabular}{lrrr}
\hline Stations & $\begin{array}{r}\text { Geographical } \\
\text { latitude }\left({ }^{\circ} \mathrm{N}\right)\end{array}$ & $\begin{array}{r}\text { Geographical } \\
\text { longitude }\left({ }^{\circ} \mathrm{E}\right)\end{array}$ & $\begin{array}{r}\text { Magnetic } \\
\operatorname{dip}\left({ }^{\circ} \mathrm{N}\right)\end{array}$ \\
\hline Calcutta & $22.58^{\circ}$ & $88.38^{\circ}$ & $33.82^{\circ}$ \\
Baharampore & $24.09^{\circ}$ & $88.25^{\circ}$ & $34.73^{\circ}$ \\
Farakka & $24.79^{\circ}$ & $87.89^{\circ}$ & $36.04^{\circ}$ \\
Siliguri (N.B.U.) & $26.72^{\circ}$ & $88.39^{\circ}$ & $39.49^{\circ}$ \\
\hline
\end{tabular}

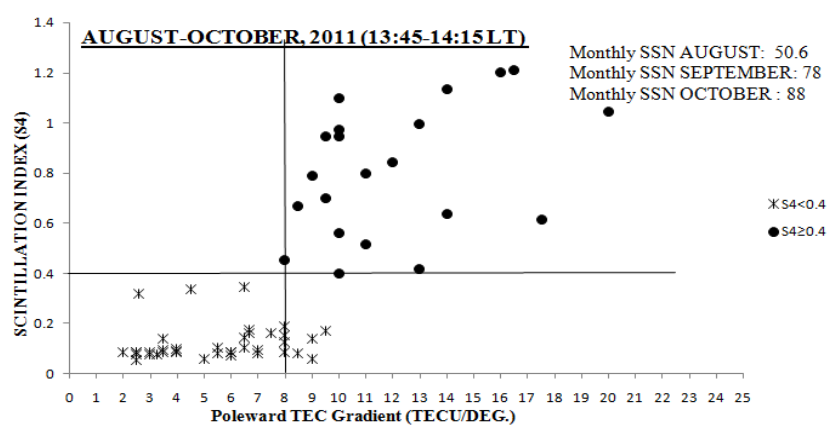

(a)

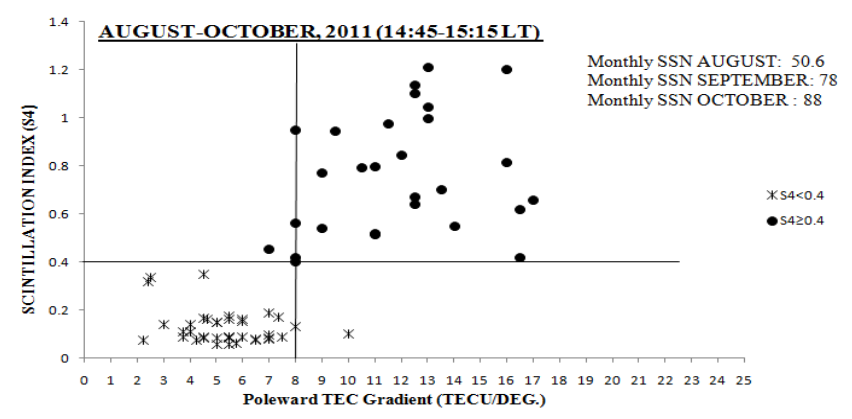

(b)

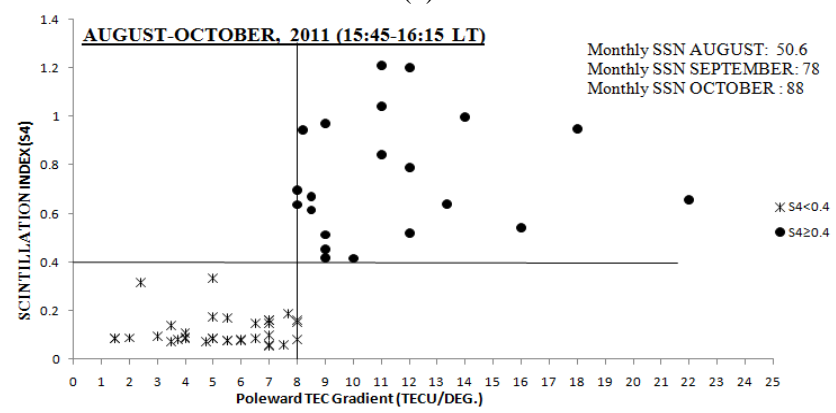

(c)

Fig. 5. (a-c) Correlation of poleward gradient of EIA calculated at 14:00, 15:00 and 16:00 LT, respectively, over subionospheric latitude $24^{\circ}-27^{\circ} \mathrm{N}$ and longitude swath $88.5^{\circ} \mathrm{E}$ on different days of August-October 2011 with GPS scintillation $\left(S_{4} \geq 0.4\right)$ around the northern crest of the EIA $\left(350 \mathrm{~km}\right.$ subionospheric swath $21.5^{\circ}-$ $\left.23.5^{\circ} \mathrm{N}, 87.5^{\circ}-89.5^{\circ} \mathrm{E}\right)$.

and March-April 2012, the threshold equatorward TEC gradients are $7 \mathrm{TECU} \mathrm{deg}^{-1}$ and $9.5 \mathrm{TECU} \mathrm{deg}^{-1}$, respectively. The corresponding gradients on the poleward side are 8 and 11 TECU deg ${ }^{-1}$. Chi-square $\left(\chi^{2}\right)$ test was performed with these threshold values to correlate occurrence of scintillation at Calcutta with $S_{4} \geq 0.4$ and the equatorward TEC gradients at 14:00, 15:00 and 16:00 LT respectively for each equinox. A highly significant association at $1 \%$ level is noted at 14:00, 15:00 and 16:00 LT during March-April 2011 and at 0.1\% level during August-October 2011 and March-April 2012.

Comparing the equatorward side TEC gradient with poleward side gradient, it is found that TEC gradients for the 


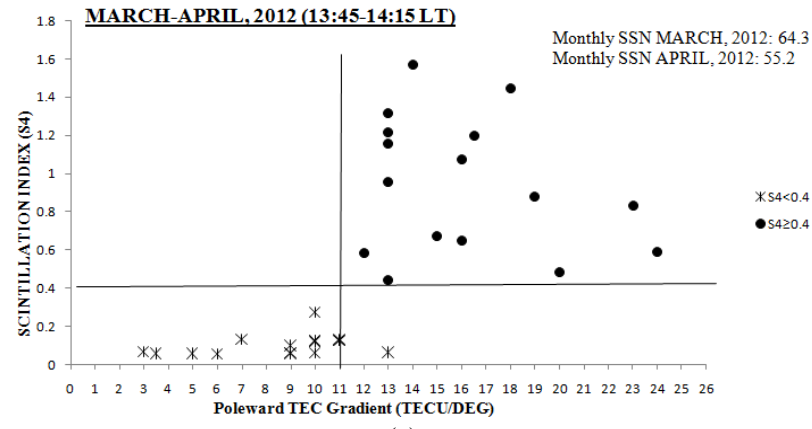

(a)

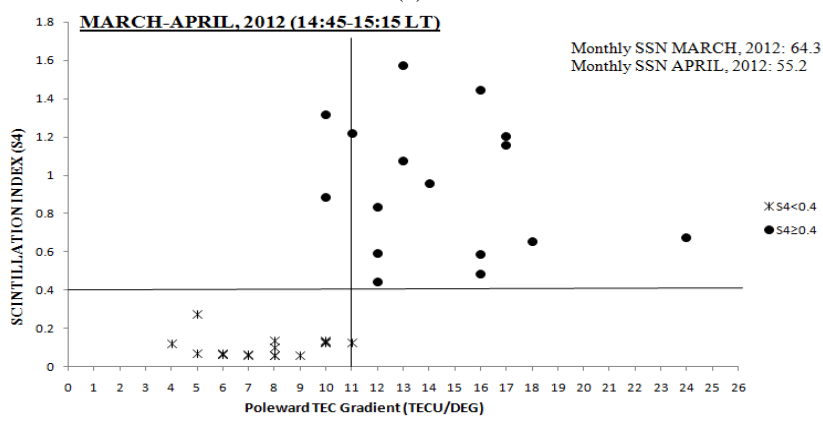

(b)

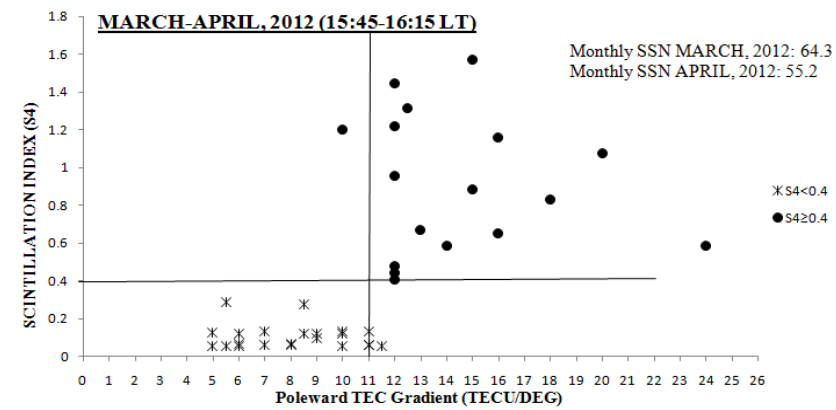

(c)

Fig. 6. (a-c) Correlation of poleward gradient of EIA calculated at 14:00, 15:00 and 16:00 LT, respectively, over subionospheric latitude $24^{\circ}-27^{\circ} \mathrm{N}$ and longitude swath $88.5^{\circ} \mathrm{E}$ on different days of 17 March-30 April 2012 with GPS scintillation $\left(S_{4} \geq 0.4\right)$ around the northern crest of the EIA (350 km subionospheric swath $21.5^{\circ}$ $\left.23.5^{\circ} \mathrm{N}, 87.5^{\circ}-89.5^{\circ} \mathrm{E}\right)$.

poleward side during afternoon hours of the above equinoxes are greater. Thus poleward side TEC gradients serve as effective proxy indicators for post-sunset L-band scintillations with $S_{4} \geq 0.4$ from a station like Calcutta situated underneath the northern crest of the EIA in the Indian longitude sector.

\section{Discussions}

Effects of the sharp latitudinal gradient of TEC existing in the equatorial latitudes have a profound effect on the reliability of performance of SBAS. Several workers have studied the plausible causes and effects (Ray et al., 2006; Valladares et
Table 2. $2 \times 2$ contingency table of the two stations (Calcutta, Baharampore) for testing the null hypothesis during MarchApril 2011.

\begin{tabular}{llrrr}
\hline & & $S_{4}<0.4$ & $S_{4} \geq 0.4$ & TOTAL \\
\hline \multirow{2}{*}{ 08:00 UT } & TEC GRADIENT $<7$ & 9 & 2 & 11 \\
& TEC GRADIENT $\geq 7$ & 4 & 10 & 14 \\
\hline \multirow{2}{*}{ 09:00 UT } & TOTAL & 13 & 12 & 25 \\
& TEC GRADIENT $<7$ & 11 & 3 & 14 \\
& TEC GRADIENT $\geq 7$ & 1 & 9 & 10 \\
\hline \multirow{2}{*}{ 10:00 UT } & TOTAL & 12 & 12 & 24 \\
& TEC GRADIENT $<7$ & 11 & 0 & 11 \\
& TEC GRADIENT $\geq 7$ & 3 & 12 & 15 \\
\hline & TOTAL & 14 & 12 & 26 \\
\hline
\end{tabular}

Table 3. $2 \times 2$ contingency table of the three stations (Calcutta, Baharampore, N.B.U. Siliguri) for testing the null hypothesis during August-October 2011

\begin{tabular}{llrrr}
\hline & & $S_{4}<0.4$ & $S_{4} \geq 0.4$ & TOTAL \\
\hline 08:00 UT & TEC GRADIENT $<7$ & 30 & 0 & 30 \\
& TEC GRADIENT $\geq 7$ & 8 & 22 & 30 \\
\hline \multirow{2}{*}{ 09:00 UT } & TOTAL & 38 & 22 & 60 \\
& TEC GRADIENT $<7$ & 36 & 1 & 37 \\
& TEC GRADIENT $\geq 7$ & 2 & 27 & 29 \\
\hline \multirow{2}{*}{ 10:00 UT } & TOTAL & 38 & 28 & 66 \\
& TEC GRADIENT $<7$ & 31 & 0 & 31 \\
& TEC GRADIENT $\geq 7$ & 3 & 21 & 24 \\
\hline & TOTAL & 34 & 21 & 55 \\
\hline
\end{tabular}

al., 2001, 2004; Rama Rao et al., 2006; Ram et al., 2006; Nava et al., 2007) of such steep TEC gradients and have strived to develop a predictive mechanism for occurrence for post-sunset scintillations. These exercises have mostly been restricted to the region between the magnetic equator and the northern and southern crests of EIA. Paul et al. (2011) utilized TEC measurements from a meridional chain of stations along $77^{\circ}$ E under the Indian SBAS GAGAN to study the different latitudinal gradients of TEC existing on either side of the northern crest. The latitudinal gradient of TEC beyond the northern crest of EIA was found to be sharper than that on the equatorward side of the crest, in conformity with the earlier suggestions of Rastogi and Klobuchar (1990). However, to the best our knowledge, correlation of the poleward gradient of TEC during afternoon hours with occurrence of post-sunset L-band scintillations has not been reported in literature. The present paper reports the results of a novel experiment conducted over two equinoxes of 2011 and the vernal equinox of 2012 to establish conclusively a quantitative relation between the poleward latitudinal gradient of TEC measured during the afternoon hours with the occurrence of 
Table 4. $2 \times 2$ contingency table of the three stations (Calcutta, Farakka, N.B.U. Siliguri) for testing the null hypothesis during March-April 2012.

\begin{tabular}{llrrr}
\hline & & $S_{4}<04$ & $S_{4} \geq 0.4$ & TOTAL \\
\hline 08:00 UT & TEC GRADIENT $<7$ & 13 & 0 & 13 \\
& TEC GRADIENT $\geq 7$ & 4 & 16 & 20 \\
\hline \multirow{2}{*}{ 09:00 UT } & TOTAL & 17 & 16 & 33 \\
& TEC GRADIENT $<7$ & 16 & 2 & 18 \\
& TEC GRADIENT $\geq 7$ & 1 & 14 & 15 \\
\hline \multirow{2}{*}{ 10:00 UT } & TOTAL & 17 & 16 & 33 \\
\hline & TEC GRADIENT $<7$ & 18 & 1 & 19 \\
& TEC GRADIENT $\geq 7$ & 4 & 16 & 20 \\
\hline & TOTAL & 22 & 17 & 39 \\
\hline
\end{tabular}

Table 5. Chi-square $\left(\chi^{2}\right)$ values for the above stations during the equinoctial periods of March-April 2011 and 2012, and AugustOctober 2011.

\begin{tabular}{lrrr}
\hline & $08: 00$ UT & 09:00 UT & 10:00 UT \\
\hline March-April 2011 & 6.9 & 10.9 & 16.3 \\
August-October 2011 & 34.7 & 54.4 & 43.9 \\
March-April 2012 & 20.2 & 22.1 & 22.1 \\
\hline
\end{tabular}

post-sunset scintillations from a station Calcutta situated near the northern crest of EIA in the geophysically sensitive Indian longitude sector. The present forecasting technique was able to identify threshold values of 7,8 and $11 \mathrm{TECU} \mathrm{deg}^{-1}$ for latitudinal gradients of TEC measured at 14:00, 15:00 and 16:00 LT for the above three equinoxes respectively, which were subsequently followed by occurrence of post-sunset Lband scintillations with $S_{4 \max } \geq 0.4$ over the time interval 18:00 to 06:00 LT. The present technique provides a maximum lead time of $4 \mathrm{~h}$ and a minimum of $2 \mathrm{~h}$ for L-band scintillation prediction. Further, for stations located beyond the northern crest of the EIA in the Indian longitude sector like Delhi, Simla, Baharampore and Siliguri, this technique could be effectively used as a precursor for post-sunset Lband scintillation.

Acknowledgements. This research has been sponsored in part by the Indian Space Research Organization (ISRO) through the CAWSES India Phase II Research Project and the Asian Office of Aerospace Research and Development (AOARD) through the SCINDA program. The authors would like to acknowledge the support extended by the Principal of K. N. College, Baharampore, Bharat Sevashram Sangha, Farakka, and the Head of Department of Physics, North Bengal University, India, for conducting the experiments and campaigns.

Topical Editor K. Hosokawa thanks H. Chandra and one anonymous referee for their help in evaluating this paper.

\section{References}

Breed, A. M., Goodwin, A. L., Vandenberg, A. M., Essex, E. A., Lynn, K. J. W., and Sylby, J. N.: Ionospheric total electron content and slab thickness determined in Australia, Radio Sci., 32, 1635-1643, 1997.

Nava, B., Radicella, S. M., Leitinger, R., and Coïsson, P.: Use of total electron content data to analyze ionosphere electron density gradients, Adv. Space Res., 39, 1292-1297, 2007.

Paul, A., Das, A., and DasGupta, A.: Characteristics of SBAS grid sizes around the northern crest of the equatorial ionization anomaly, J. Atmos. Sol. Terr. Phys., 73, 1715-1722, 2011.

Raghavarao, R., Nageswararao, M., Sastri, J. H., Vyas, G. D., and Sriramarao, M.: Role of equatorial ionization anomaly in the initiation of equatorial spread-F, J. Geophys. Res., 93, 5959-5964, doi:10.1029/JA093iA06p05959, 1988.

Rama Rao, P. V. S., Gopi Krishna, S., Niranjan, K., and Prasad, D. S. V. V. D.: Study of spatial and temporal characteristics of Lband scintillations over the Indian low-latitude region and their possible effects on GPS navigation, Ann. Geophys., 24, 15671580, doi:10.5194/angeo-24-1567-2006, 2006.

Rastogi, R. G. and Klobuchar, J. A.: Ionospheric Electron Content Within the Equatorial F2 Layer Anomaly Belt, J. Geophys. Res., 95, 19045-19052, 1990.

Ray, S., Paul, A., and DasGupta, A.: Equatorial scintillations in relation to the development of ionization anomaly, Ann. Geophys., 24, 1429-1442, doi:10.5194/angeo-24-1429-2006, 2006.

Tulasi Ram, S., Rama Rao, P. V. S., Niranjan, K., Prasad, D. S. V. V. D., Sridharan, R., Devasia, C. V., and Ravindran, S.: The role of post-sunset vertical drifts at the equator in predicting the onset of VHF scintillations during high and low sunspot activity years, Ann. Geophys., 24, 1609-1616, doi:10.5194/angeo-241609-2006, 2006.

Valladares, C. E., Basu, S., Groves, K., Hagan, M. P., Hysell, D. D., Mazella Jr., A. J., and Sheehan, R. E.: Measurement of the latitudinal distributions of total electron content during equatorial spread F events, J. Geophys. Res., 106, 29133-29152, doi:1029/2000JA000426, 2001.

Valladares, C. E., Seehan, R., and Villalobos, J.: A latudinal network of GPS receivers dedicated to studies of equatorial spread F, Radio Sci., 39, RS1S23, doi:10.1029/2002RS002853, 2004. 